\title{
INVESTIGATION OF MECHANICAL BEHAVIOUR OF SISAL BAMBOO AND EPOXY REINFORCED NATURAL COMPOSITE
}

\author{
Gobi K \\ Department of Mechanical Engineering \\ P.A. College of Engineering and Technology, \\ Pollachi, Coimbatore, India. \\ Amaresh D \\ Department of Mechanical Engineering \\ P.A. College of Engineering and Technology, \\ Pollachi, Coimbatore, India.
}

\begin{abstract}
Now-a-days, The natural sisal/bamboos from renewable natural resources offer the potential to act as a reinforcing material for polymer composites alternative to the use of glass, carbon and wood. Among various natural fibers, sisal or bamboo is most widely used natural fiber due to its advantages like easy availability, low density, low production cost and satisfactory mechanical properties. For a composite material, its mechanical behavior depends on many factors such as fiber content, orientation, types, length etc. Attempts have been made in this research work to study the effect of loading on the physical and mechanical behavior of sisal/bamboo reinforced epoxy-based hybrid composites.
\end{abstract}

Key words: Sisal, Bamboo, Epoxy, Composite.

\section{INTRODUCTION}

Mankind has been aware composite materials since several hundred years before Christ and applied innovation to improve the quality of life. Although it is not clear has to how Man understood the fact that mud bricks made sturdier houses if lined with straw, he used them to make buildings that lasted. Ancient Pharaohs made their slaves use bricks with to straw to enhance the structural integrity of their buildings, some of which testify to wisdom of the dead civilization even today. Contemporary composites result from research and innovation from past few decades have progressed from bamboo sisal/bamboo for automobile bodies to particulate composites for aerospace and a range other application. Ironically, despite the growing familiarity with composite materials and everincreasing range of applications, the term defines a clear definition. Loose terms like "materials composed of two or more distinctly identifiable constituents" are used to describe natural composites like timber, organic materials, like tissue surrounding the skeletal system, soil aggregates, minerals and rock.

Composites that form heterogeneous structures which meet the requirements of specific design and function, imbued with desired properties which limit the scope for classification. Reinforcing materials generally withstand maximum load and

\author{
Kaleeswaran M \\ Department of Mechanical Engineering \\ P.A. College of Engineering and Technology, \\ Pollachi, Coimbatore, India. \\ Dhanush R \\ Department of Mechanical Engineering \\ P.A. College of Engineering and Technology, \\ Pollachi, Coimbatore, India.
}

serve the desirable properties. Further, though composite types are often distinguishable from one another, no clear determination can be really made. The demands on matrices are many. They may need to temperature variations, be conductors or resistors of electricity, have moisture sensitivity etc. This may offer weight advantages, ease of handling and other merits which may also become applicable depending on the purpose for which matrices are chosen. Solids that accommodate stress to incorporate other constituents provide strong bonds for the reinforcing phase are potential matrix materials. A few inorganic materials, polymers and metals have found applications as matrix materials in the designing of structural composites, with commendable success. These materials remain elastic till failure occurs and show decreased failure strain, when loaded in tension and compression. Composites cannot be made from constituents with divergent linear expansion characteristics. Choice of fabrication method depends on matrix properties and the effect of matrix on properties of reinforcements. It is desired to produce low cost, high quality, sustainable and environmentally friendly materials. It has been found from the researched study that the lower mechanical properties and poor compatibility between polymer matrix and fibers. Composite materials are one of the most favored solutions to this problem in the field. By combining the stronger properties of traditional materials and eliminating the disadvantages they bear, fiber mats of different orientations are developed, composite materials technology is providing compromising solutions and alternatives to many engineering fields. Problems born from material limitations like heavy weight, structural strength, and thermal resistance are being solved by the composite material alternatives, and many more alternatives are being introduced to readily use engineering applications.

Natural fibers such as sisal, bamboo, coir and jute can be used successfully in composite components in order to realize reduction of weight and cost. These fibers are renewable, non-abrasive to Process equipment, and can be incinerated at the end of their life cycle for energy recovery as they possess a good deal of calorific value. They are also very safe during handling, processing and use. The distinctive properties of natural fiber reinforced polymers are improved 


\section{International Journal of Engineering Applied Sciences and Technology, 2021 \\ Vol. 5, Issue 12, ISSN No. 2455-2143, Pages 307-310 \\ Published Online April 2021 in IJEAST (http://www.ijeast.com)}

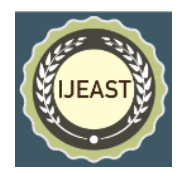

tensile and bending strength, greater ductility and greater resistance to cracking and hence improved impact strength and toughness. By changing the direction of the fibers in the resin, the material properties can be tailored to the external loads. To optimize the construction multiple adjusted layers (laminate) can be used to form a laminate. By this joining, the poor capabilities and drawbacks of the individual components disappear. By this joining, the poor capabilities and drawbacks of the individual components disappear. For instance, composites combine a high stiffness and strength with a low weight and their corrosion resistance is often excellent. Composites have worked their way up amongst wood and metal due to their outstanding price performance ratio during a lifetime. A powerful approach in improving this ratio is to minimize the steps required from raw material to end product.

\section{A. LITERATURE REVIEW}

1) R. Prasanna Venkatesh, K. Ramanathan, V. Srinivasa Raman- In this paper, tensile, flexural, impact properties and water absorption tests were carried out using sisal/unsaturated polyester composite material. Initially the optimum fiber length and weight percentage are estimated. To improve the tensile, flexural and impact properties, sisal fiber was hybridized with bamboo fiber. This work shows that the addition of bamboo fiber in sisal/ unsaturated polyester composites of up to $50 \%$ by weight results in increasing the mechanical properties and decreasing the moisture absorption property. In this research work, the effects of fiber treatment and concentration on the mechanical properties of a short natural fiber reinforced polyester hybrid composite are investigated. The fibers were subjected to $10 \%$ sodium hydroxide solution treatment for 24 h. The mechanical properties of composites with treated fibers are compared with untreated fiber composites. The fractured surface of the treated fiber composite specimen was studied using Scanning Electron Microscopy (SEM). The treated hybrid composite was compared with an untreated hybrid composite, with the former showing a $30 \%$ increase in tensile strength, $27.4 \%$ - in flexural strength, and $36.9 \%$ - in impact strength, along with an extreme decrease in moisture absorption behavior.

2) Pankaj G. Bedmutha, Pratik M. Waghmare, ShrishailB.Sollapur- This paper describes mechanical properties and Design analysis of Bamboo Fibre Reinforced Biodegradable Plastics. Natural fibre has emerged as a renewable and cheaper substitute to synthetic materials such as glass, carbon. This increases tensile strength of composite. Compressive strength is not significantly increased. Bamboo fibres are eco-friendly and can be used in polymer composite.

\section{SISAL RESOURCE}

Sisal made from the large spear shaped tropical leaves of the Agave Sisal plant. Sisal is extracted by a process known as decortications, where leaves are crushed and beaten by a rotating wheel set with blunt knives, so that only fibers remain. In East Africa, where production is typically on large estates, the leaves are transported to a central decortication plant, where water is used to wash away the waste parts of the leaf. The fiber is then dried, brushed and baled for export. Superior quality sisal is found in East Africa, once washed and decorticated.
Proper drying is important as fiber quality depends largely on moisture content. Artificial drying has been found to result in generally better grades of fiber than sun drying, but is not feasible in the developing countries where sisal is produced. In the dryer climate of north-east Brazil, sisal is mainly grown by smallholders and the fiber is extracted by teams using portable raspadors which do not use water. Sisal is subsequently cleaned by brushing. Dry fibers are machine combed and sorted into various grades, largely on the basis of the previous in-field separation of leaves into size groups.

\section{A. DRAWBACKS OF SISAL}

Sisal is not recommended for areas that receive wet spills, or rain or snow. It absorbs air humidity leading to a small amount of expanding and contracting (rugs and unsecured edges may curl). Sisal is too tough for textiles and fabrics. It is not suitable for a smooth wall finish. It is reported that some plantations have destroyed natural forests to agricultural land.

\section{BAMBOO FIBER}

The bamboo fiber is made from the starchy pulp of bamboo plants. This textile fiber is fabricated from natural bamboo and other additives. In fact, bamboo fiber is a regenerated cellulose fiber, which is produced from bamboo pulp, processed from bamboo culms. It looks like cotton in its un-spun form. Many bamboo fiber manufacturers apply extensive bleaching processes to turn the color of bamboo fiber into white. However, the companies engaged in producing organic bamboo fabric leave the bamboo fiber unbleached. Bamboo fiber is thinner as compared to hair and has a round and smooth surface which makes it abrasion proof.

\section{A. EXTRACTION OF BAMBOO}

Two types of processing are done to obtain bamboo fibers

- Mechanical Processing

- Chemical Processing

However, in both the processes, the raw bamboo has to be split to get bamboo strips. After that, bamboo fiber is extracted either through chemical or mechanical processing.

Chemical Processing: It is basically hydrolysis alkalization. The crushed bamboo is "cooked" with the help of Sodium hydroxide $(\mathrm{NaOH})$ which is also known as caustic soda or lye into a form of regenerated cellulose fiber. Hydrolysis alkalization is then done through carbon disulfide combined with multi-phase bleaching. Although chemical processing is not environmentally friendly but it is preferred by many manufacturers as it is a less time-consuming process.

Mechanical Processing: In this method, the crushed bamboo is treated with biological enzymes. This breaks the bamboo into a mushy mass and individual fibers are then combed out. Although expensive, this process is ecofriendly.

\section{WORKING}

The sisal/bamboo is collected from local sources. Sisal/bamboo and Epoxy resin is purchased from market is used for fabrication of composite. The low temperature curing epoxy 


\section{International Journal of Engineering Applied Sciences and Technology, 2021 \\ Vol. 5, Issue 12, ISSN No. 2455-2143, Pages 307-310 \\ Published Online April 2021 in IJEAST (http://www.ijeast.com)}

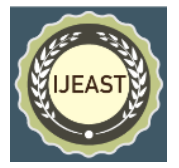

resin and corresponding hardener are mixed in a ratio of 10:1 by weight as recommended. A mould is used for casting the composite slabs. The short sisal/bamboo is mixed with epoxy resin by the simple mechanical stirring. The composites are prepared with three different sisal/bamboo loading and four different sisal/bamboo lengths keeping sisal/bamboo content constant (20\% wt.) using simple hand lay-up technique. The mixture is poured into various moulds confirming to the requirements of various testing conditions and characterization standards. The detailed composition and designation of the composites are presented. The cast of each composite is preserved under a load of about $25 \mathrm{~kg}$ for 36 hours before it removed from the mould cavity. Then this cast is post cured in the air for another 36 hours after removing out of the mould. Specimens of appropriate dimension are cut for physical and mechanical tests.

\section{A. ADVANTAGES}

- It has low density and high specific strength.

- It is a biodegradable renewable resource.

- It provides thermal and acoustic insulation.

\section{B. DISADVANTAGES}

- Decomposition in alkaline environments (or) in biological attack.

- It is very much bad in torsion when it became mature.

- Probability of decomposition in biological attack.

\section{CONCLUSION}

The material selection and properties of sisal/bamboo fiber reinforced epoxy-based hybrid composites has been obtained till now with the help of various journals. Reinforcement preparation and test results are yet to be obtained in future.

The present work showed the usefulness of sisal fiber as reinforcement to other natural fiber material. The tensile, hardness, and compression tests if sisal/bamboo fiber will be conducted using UTM machine. Further work must be done related to fiber surface treatment and residue elimination in recycled HDPE (High-density polyethylene) to improve mechanical properties.

\section{REFERENCES}

[1] Verma D., Gope P.C., Shandilya A., Gupta A., Maheshwari M.K., (2013). Coir FIBER Reinforcement and Application in Polymer Composites: A Review, J. Mater. Environ. Sci 4(2), (pp. 263-276).

[2] Sahib D.N and Jog J. P., (1999). Natural FIBER Polymer Composites: A Review, Advances in Polymer Technology, 18(4), (pp.351-363).

[3] Malik P.K. FIBER reinforced Composites: Materials, Manufacturing and Design. John M.J., Anandjiwala R.D., (2008). Recent developments in chemical modification and characterization of natural FIBER- reinforced composites, Polymer Composites, 29(2), (pp. 187-207).

[4] Ronga M.Z., Zhang M.Q., Liu Y., Yang G.C., Zeng H.M., (2001). The effect of FIBER treatment on the mechanical properties of unidirectional sisal reinforced epoxy composites, Composites Science and Technology 61, (pp.1437-1447).

[5] Yuvaraj G., Vijaya Ramnath B., Abinash, Srivasan B., Vikas Nair R., (2016). Investigation of Mechanical Behavior of Sisal Epoxy Hybrid Composites. (DOI No.10.17485/ijst/2016/v9i34/101004).

[6] Towo AN., Ansell MP., (2008). Fatigue evaluation and dynamic mechanical thermal analysis of sisal fibre-thermo setting resin composites. Composite Science and Technology. (68(9):25-32).

[7] Harelrushna Sutar., Prakash Chandra Sahoo., Prateeksha Suman Sahu., Surajabala Sahoo, Rabiranjan Murmu., Sumit Swain., Subash Chandra Mishra., (2018). Mechanical, Themal And Crystallization Properties of Polypropylene (PP) Reinforced Composites with High Density Polyethylene (HDPE) as Matrix, (DOI N0.10.4236/msa.2018.95035).

[8] Daniel B.S.S., and Chaudhari G.P., (2012). Physical and Mechanical Properties of Epoxy-Nanoparticulate Composite Adhesive.

(DOI No.10.4028/www.scientific.net/AMR.585.297).

[9] Herng-Chia Hsieh., and Muhammad Yahaya., (2020). The Mechanical Properties of Sisal/PMMA and Sisal/Carbon/PMMA Biomedical Composites. (DOI No.10.4028/www.scientific.net/KEM.846.181).

[10] Noorunnisa Khanam P., Abdul Khalil HPS., Ramachandra Reddy G., Venkata Naidu S., (2011). Tensile, Flexural and Chemical Resistance Properties of Sisal Fiber Reinforced Polymer Effect of Fibre Surface Treatment. Journal of Polymers and the Environment. (DOI No.10.1007/s10924-010-0219-7).

[11] Arthanarieswaran V.P., Kumaravel A., Kathirselvam M., (2014). Evaluation of Mechanical properties of banana and sisal fiber reinforced epoxy composites: Influence of glass fiber hybridization. (DOI No.10.1016/j.matdes.2014.07.058).

[12] Murali Mohan Rao K., Mohana Rao K., Ratna Prasad A.V., (2010). Fabrication and testing of natural fiber composites: Vakka, sisal, bamboo and banana. Materials and Design. (DOI No.10.1016/j.matdes.2009.06.023).

[13] Li Y., Mai Y-W., Ye L., (2000). Sisal Fiber and its composites: a review of recent developments, Composites Science and Technology. (DOI No.10.1016/S0266-3538(00)00101-9).

[14] Hari Om Maurya., Gupta M.K., Srivastava R.K., Singh H., (2015). Study on the Mechanical Properties of Epoxy Composites using Short Sisal Fiber. (DOI No. 10.1016/j.matpr.2015.07.053).

[15] Ratna Prasad A.V., Mohana Rao K., (2011). Mechanical properties of natural fibre reinforced polyester composites: Jowar, sisal and bamboo. (DOI No.10.1016/j.matdes.2011.03.015). 
International Journal of Engineering Applied Sciences and Technology, 2021

Vol. 5, Issue 12, ISSN No. 2455-2143, Pages 307-310

Published Online April 2021 in IJEAST (http://www.ijeast.com)

[16] Alateyah A.I., (2019). High-Density Polyethylene Based on Exfoliated Graphite Nanoplatelets/NanoMagnesium Oxide: An Investigation of Thermal
Properties and Morphology, (DOI No.10.4236/msa.2019.103013). 